\title{
ACESSO BICORONAL PARA TRATAMENTO DE FRATURA PAN-FACIAL
}

Diego José STRINGHINI, Paulo Roberto MULLER, Fernando ANTONINI, Nelson Luis Barbosa REBELLATO, Felipe BERNABE, Leandro Eduardo KLUPPEL

Com o dinamismo da sociedade contemporânea os traumas acabam tendo grande importância e prevalência dentro dos serviços de pronto atendimento dos hospitais. Segundo dados da Organização Mundial de Saúde, os traumas estão entre as principais causas de morte e morbidade no mundo. Dentre os diversos tipos, o trauma de face destaca-se pela sua importância, uma vez que apresenta repercussões emocionais, funcionais e muitas vezes deformidades permanentes. A grande prevalência de lesões em face se deve a grande exposição dessa área corporal e a falta de proteção, o que acarreta muitas vezes em lesões graves.Trata-se de um trauma de abrangência multidisciplinar, envolvendo principalmente as especialidades de cirurgia geral, oftalmologia, cirurgia plástica, cirurgia buco-maxilo-facial e neurocirurgia. $O$ objetivo desse trabalho é mostrar um caso clínico de um paciente atendido na emergência do Hospital de Fraturas da XV em Curitiba, o qual havia sofrido um trauma em face decorrente de acidente de trabalho. Após exame tomográfico verificou-se múltiplas fraturas em face, fratura naso-orbito-etmoidal, assoalho de órbita direito, Le fort-II e frontal. Ele foi então submetido a cirurgia sob anestesia geral, na qual realizado o acesso bicoronal para redução e fixação interna rígida das fraturas.

Palavras-chave: Fraturas; Face; Imagem. 